\title{
La Historia magistra vitae y el practical past
}

\section{History Magistra Vitae and the Practical Past}

\author{
Perla Chinchilla \\ Departamento de Historia-Universidad Iberoamericana \\ México \\ Correo:perla.chinchilla@ibero.mx
}

DOI 10.48102/hyg.vi55.327

\section{ABSTRACT}

In his book The Practical Past White makes a diagnosis of the aporia that history has reached as scientific historiography from his perspective, and proposes, from the category of Practical Past, how to explain this course, how to recover his guiding social function of action. Then I will try to synthesize why historiography, from its perspective, took off from that Practical Past throughout the Nineteenth and Twentieth centuries, until it is currently disconnected from it, given the impossibility of converting it, both as an "object of study", on the one hand, as, when separating from the present, abandoning its ancestral role of moral guidance - History Magistra Vitae-, on the other.

Keywords: Practical Past, History Magistra Vitae, Fiction, Truth, Postmodern Novel.

\section{Resumen}

En su libro The Practical Past White hace un diagnóstico de las aporías a las que desde su perspectiva ha llegado la historia como historiografía científica, y propone, a partir de la categoría de practical past, cómo explicar este decurso, cómo recuperar su función social de guía de la

* Agradezco a Andrés Gordillo López su generoso e inteligente apoyo en la investigación sobre las novelas citadas en este texto. 
acción. En estas páginas intentaré sintetizar el porqué la historiografía, desde su perspectiva, se fue despegando de ese practical past a lo largo de los siglos XIX y xx, hasta quedar en la actualidad desvinculada del mismo, ante la imposibilidad de convertirlo, tanto en "objeto de estudio", por un lado, como, al separarse del presente, abandonando su ancestral papel de guía moral -la historia magistra vitae-, por otro.

Palabras clave: pasado práctico, historia magistra vitae, ficción, verdad, novela posmoderna.

Artículo recibido: 27/01/2020

Artículo aceptado: 3/03/2020

$\mathrm{H}$

ace ya más de una década, en las páginas de esta misma revista publiqué el artículo titulado "Aprender Historia o aprender de la Historia”, el cual iniciaba así:

En este ensayo quiero resaltar, sin embargo, un "síntoma" inesperado -tal vez una anomia no resuelta hasta nuestros días-, y es justamente la pervivencia aparentemente anacrónica del topos de la historia magistra vitae, que según el diagnóstico de Koselleck debía haber desaparecido hace más de un siglo. Desde esta "anomalía” podemos iluminar algunos aspectos tanto de la escritura de la historia como de nuestra sociedad. Pretendo mostrar una extrañeza, ante una práctica social supuestamente superada, o vista como residuo de una historia nacionalista trasnochada que hay que eliminar a la mayor brevedad -a través de la cual los héroes aparecen como ejemplos a seguir y la experiencia histórica es la guía de la sociedad- pero para la cual parecemos no haber encontrado un sustituto adecuado. ${ }^{1}$

Y concluía de esta forma:

${ }^{1}$ Perla Chinchilla Pawling, “¿Aprender de la historia o aprender historia?”, p. I 20. Véase una aproximación sobre el tema en Verónica Tozzi, "Hayden White y el pluralismo conversacional". 
Queda en el tintero el problema -agudo y urgente- de la historia magistra "para los países donde existe la fuerza o la evidencia de que el porvenir está en juego", y esto vale especialmente -como señala Hartog ${ }^{2}$ - para los países antes colonizados, como es "nuestro" México. Híbrido entre la sociedad moderna y la tradicional, parece tener una doble complejidad pensar el papel de esta historia en las aulas, en las que se reproducen los lugares comunes de la modernidad europea -libertad, democracia, derechos humanos, nacionalismo, etcétera- sin que se anclen en la tradición propia (que en un país colonizado no es fácil re-conocer) y mucho menos en la esquizofrénica experiencia cotidiana. ${ }^{3}$

Años después, en el número 32 de la misma revista, Hayden White nos hizo el honor de contribuir con un artículo para el expediente a mi cargo, "Géneros históricos", en el que me dio nuevas pistas para continuar con la reflexión sobre el lugar social de la Historia Maestra de Vida. Y justo, en este trabajo conmemorativo, diez años después, con su practical past, cierro este círculo dorado, en un punto en el que se ilumina la vía por donde podría restituirse -guardadas todas las diferencias- una historia magistra vitae en la actualidad.

A caminar este trayecto reflexivo dedico las siguientes páginas, elaboradas en forma de glosa, con la finalidad de mostrar y sintetizar los argumentos de White, en apoyo y ampliación de mi original pregunta.

\section{1) Historical past Y PRACTICAL PAST}

En su libro The Practical Past White hace un diagnóstico de las aporías a las que desde su perspectiva ha llegado la historia como historiografía científica, y propone, a partir de la categoría de

2 "François Hartog: el nacimiento del discurso histórico occidental", pp. I 68-I69. ${ }^{3}$ Ibidem, p. I 50. 
practical past, cómo explicar este decurso, cómo recuperar su función social de guía de la acción. Cito in extenso su aproximación a este concepto:

¿Qué es el pasado práctico? El concepto proviene de algunos de los escritos tardíos del filósofo político Michael Oakeshott, y se refiere a aquellas nociones del "pasado" que todos nosotros acarreamos en nuestra vida diaria y a las que acudimos -willy-ni$l l y$ - del mejor modo que podemos en busca de información, ideas, modelos, fórmulas y estrategias para resolver todos los problemas prácticos - desde asuntos personales hasta grandes programas políticos- con los que nos topamos en aquello que de alguna forma concebimos como nuestra "situación" presente. Acudimos a este pasado sin mucha autoconciencia cuando se trata de asuntos prácticos, tales como recordar cómo arrancar un automóvil, cómo hacer una división larga, cómo cocinar un omelette, y así sucesivamente. Pero este pasado práctico es también el pasado reprimido, la memoria, el sueńo y el deseo, así como el de la resolución de problemas, de estrategias y tácticas para vivir tanto personal como comunitariamente. ${ }^{4}$

A continuación intentaré sintetizar el porqué la historiografía, desde su perspectiva, se fue despegando de ese practical past a lo largo de los siglos xix y xx, hasta quedar en la actualidad desvinculada del mismo, ante la imposibilidad de convertirlo, tanto en "objeto de estudio", por un lado, como, al separarse del presente,

4 "Oakeshott ha sugerido que, además del pasado en su totalidad y del pasado histórico, debemos tomar en consideración lo que él llama 'el pasado práctico' de las personas, grupos, instituciones y agencias particulares -es decir, el pasado al que las personas en cuanto individuos o miembros de grupos recurren para ayudarse a valorar y tomar decisiones en la vida cotidiana ordinaria, así como en situaciones extremas (tales como catástrofes, desastres, batallas, conflictos judiciales y otra clase de conflictos en que la supervivencia está en entredicho)". Hayden White, The Practical Past, p. xiii. Podría pensarse como "memoria social”, si bien esta analogía habría que desarrollarla mucho más. [Todas las traducciones de esta fuente son mías]. 
abandonando su ancestral papel de guía moral, por otro. Todo ello, ante su creciente compromiso con el "pasado histórico" (historical past), el "evento histórico"5 (historical event) y la "verdad científica" (scientific truth), en una concepción reducida de lo factual, del presente y de lo ficcional, lo cual la ha llevado a este -que podríamos denominar siguiendo a White- "limbo" entre lo cognitivo y lo práctico. Su argumento central es que la historiografía logró su constitución como una disciplina científica -o "paracientífica" - a lo largo del xix a costa de separarse de su "milenaria asociación" con la retórica, si bien, como el propio White lo sostuviera desde su trabajo pionero de Metahistory, la escritura de la historia, por más científica que sea, no puede abandonar su adscripción a la literatura de muy diversas formas. A partir de ese diagnóstico, analiza las consecuencias de esta desvinculación, mismas que podemos dividir en cognitivas y prácticas, si bien están imbricadas, como adelante se mostrará.

Entramos así en el historical past, del que distingue, por un lado, el practical past, si bien propone la existencia de otros múltiples pasados que la historiografía ha anulado:

El uso del término "histórico" como modificador del sustantivo "pasado" indica una exclusión y una condensación: una exclusión de cualquier otro pasado que no sea el "histórico", y una condensación del pasado como únicamente histórico. A partir de entonces, el pasado de la naturaleza, de la animalidad y de la humanidad, incluso los pasados de todas aquellas "historias" que existieron antes de la invención de la "Historia", serán apartados y medidos, por su verdad y su realidad, frente al pasado puro de la "historia". ${ }^{6}$

\footnotetext{
5Se usará en el texto el concepto de "evento histórico" en vez de "hecho histórico" para homologarlo con el que usa White de "historical event". El de "fact" lo he traducido por "acontecimiento".

${ }^{6}$ White, The Practical Past, op. cit., pp. I9-1 8.
} 
Pero, ¿cómo se constituyó esa separación entre los pasados práctico e histórico, y se configuró la "historia/ciencia" frente a la "literatura/arte"?, y ¿cómo propone White salir de esta aparente aporía? Podemos adelantar que es a partir de una doble "des-retorización": la de la historiografía, por una parte, y la de la propia literatura, por otra. Con este novedoso argumento, desarrollado por White en este texto, obtenemos una posible salida del actual limbo historiográfico, y una propuesta para desarrollar una nueva historia magistra, de la mano de la "novela posmoderna". Me parece que el hallazgo de White respecto a cómo puede convertirse este tipo de novela en la "Maestra" de la historia magistra, completa su lúcida aportación al problema. A dar cuenta de ello dedico las siguientes páginas.

\section{2) LA HISTORIA COMO CIENCIA Y EL HISTORICAL PAST}

En función de la separación entre estos dos pasados, White data y analiza las "implicaciones" de tal ruptura, la cual considera que "ha atormentado" a la filosofía de la historia desde "el inicio de la transformación de la historia de su estatus como un discurso en su estatus como una (putativa) ciencia. Este problema surgió en el temprano siglo xIx cuando, a fin de constituirse como una ciencia, la historia tuvo que ser separada y diferenciada de su anterior habitación en la retórica". ${ }^{7}$ A partir de ahí, el abandono de su función como magistra vitae se fue haciendo directamente proporcional a su aspiración científica; sin embargo, todavía entonces tal separación no se veía tan problemática:

La famosa "historia como enseñanza filosófica con ejemplos" o historia magistra vitae de la cultura europea decimonónica era la misma historia que los historiadores profesionales promovieron

${ }^{7}$ Ibidem, p. Iо.

88 / Perla Chinchilla 
como un pasado estudiado sólo por sí mismo y en sus propios términos, sine ira et studio. Pero esta aparente duplicidad por parte de los historiadores profesionales estaba por completo en consonancia con la ideología contemporánea de la ciencia, que VEÍA A LAS CIENCIAS NATURALES NO COMO OTRA COSA SINO COMO "DESinteresadas" y "PRÁcticas", O SOCIALMENTE benéficas, TODO AL MISMO TIEMPo. Tal visión de la ciencia era consistente con las FILOSOfíAS REINANTES DEL POSITIVISMO Y DEL UTILITARISMO, que contribuían a la transformación de una VISIÓN DEL MUNDO CIENTÍFICA EN UNA WELTANSCHAUUNG COMPLETA, que permitía que la "historia" en general fuera concebida como una prueba irreprochable propicia del progreso de la civilización y del triunfo de las razas blancas del mundo. ${ }^{8}$

En paralelo a ello tendríamos que añadir lo que nuestro glosado autor seńala respecto al encuadre que tales presupuestos conllevaban respecto al tipo de conocimiento producido por esa "historia científica" y, desde ahí, no sólo "qué clases de PREGUNTAS podrían ser esgrimidas para el presente del pasado, qué clase de EVIDENCIA podría ser aducida en cualquier esfuerzo de hacer preguntas adecuadas, qué podía constituir correctamente RESPUESTAS 'HISTÓRICAS' A ESAS PREGUNTAS', sino sobre todo, para lo que aquí se trata, "dónde habría de trazarse la línea para distinguir entre un uso adecuado o uno inadecuado del conocimiento 'histórico' en cualquier esfuerzo por esclarecer, o iluminar, los esfuerzos contemporáneos de responder preguntas centrales de pertinencia social y moral: lo que Kant llamaba la pregunta 'práctica' (por lo que quería decir ética), ¿qué debería(mos) hacer?”9 Así, estando aún al servicio de los emergentes estados-naciones europeos, o más bien, gracias a ello, "ciencia" y "ética" parecían converger. Con el advenimiento del siglo $\mathrm{xx}$, toda esta articulada cosmo-

${ }^{8}$ Ibidem, pp. I 5-I6. A partir de aquí empleo palabras y frases en versalitas para destacar ideas fundamentales de mi propuesta.

${ }^{9}$ Ibidem, pp. 7-8. 
visión se fue resquebrajando cada vez más, sujeta a una aguda crítica, si bien el "empiricismo" ha permitido que buena parte de la historiografía profesional continúe con la promulgación de su neutralidad ideológica aún hoy, como bien lo señala White.

Este empiricismo permitió que la historiografía profesional continuara alardeando de su neutralidad ideológica ("sólo los hechos, y nada más que los hechos") mientras desdeñaba la "filosofía de la historia" del tipo heredado de Comte, Hegel y Marx, y promovida por Spengler, Toynbee y Croce durante el periodo comprendido entre las dos Guerras Mundiales, como mera "ideología" o como profecía religiosa que se hacía pasar por "ciencia histórica". (Véase, por ejemplo, Popper y Collingwood). ${ }^{10}$

Estas rechazadas "filosofías de la historia" quedaban, sin embargo, más cercanas al practical past en términos de su aportación a una posible cosmovisión, que al historical past construido por los profesionales de la Historia. ${ }^{11}$

El camino por el que circuló White para argumentar su crítica a la historiografía profesional fue, desde el inicio de sus propuestas, la mostración de que ésta seguía estando relacionada con la retórica, debido sobre todo a su carácter narrativo. Sin embargo, esta proximidad -y aquí la distinción entre lo narrativo y lo no narrativo de la escritura de la historia ha quedado muchas veces al margen- ha sido fuertemente rechazada por una mayoría de los historiadores, quienes observan esta diferencia desde la explícita e indispensable separación entre la historiografía y la literatura - dada la doble vinculación de esta última con la retórica y con la ficción-, si es que la primera ha de conservar su carácter científico. A mostrar la falacia de estos presupuestos se ocupa White en el texto que analizamos. Aquí, dado el objetivo del mismo,

${ }^{10}$ Ibidem, p. 6.

${ }^{11}$ Idem.

90 / Perla Chinchilla 
que es explicar la separación del historical past del practical past, se centra en el aspecto epistemológico que implica suponer el acceso privilegiado a la "realidad" a partir de la concepción del "evento histórico", frente al "evento literario" que es "ficticio"; "los eventos suceden, los hechos son establecidos" nos señala, ${ }^{12}$ según la distinción decimonónica que se extiende en buena medida hasta nuestros días. La mostración de este falso supuesto se centra, en el caso del texto analizado, en el fino análisis que White lleva a cabo al referirse no ya al pretendido abandono de la retórica por parte de la historiografía científica a partir del siglo xIx -como lo argumenta en su incendiaria Metahistory de I973-, sino a la "desretorización” de la propia literatura, también bajo la pretensión del acceso a "lo real", aunque aquí de otra forma:

Pero la EXCLUSIÓN DE LA RETÓRICA (considerada como una teoría de la composición mediante la cual un cierto cuerpo de información era elaborado para usos prácticos diferentes, persuasión, incitación a la acción, inspiración de sentimientos de reverencia o de repulsión, etc.) DE LA HISTORIOLOGía tuvo un efecto en los estudios históricos muy diferente de lo que una eXCLUSIÓN SIMILAR DE LA RETÓRICA DE LA "ESCRITURA LITERARIA" HABRÍA TENIDO SOBRE LA "LITERATURA". ${ }^{13}$

Así, mientras la historiografía científica pretendía mostrar la "realidad" del pasado acudiendo a la evidencia empírica al modo de las ciencias naturales, cuya constatación dependía del "tribunal de apelación" conformado por los pares, ${ }^{14}$ la "novela realista" rechazaba la retórica bajo el principio de la pretensión de acceder también a la "realidad", pero en este caso de la sociedad del presente de su escritura.

${ }^{12}$ Ibidem, p. 45.

${ }^{13}$ Ibidem, p. 8.

${ }^{14}$ Ibidem, p. 9. 
En efecto, la novela realista llegó a ser el sitio en donde una clase dominante recién legitimada podía ensayar su rol en el drama del conflicto del deseo con necesidades que generaciones anteriores ni siquiera habían imaginado. De modo irónico, mientras más lograba la historia su propia transformación en una [suerte de] ciencia objetivista, empirista, particularista, MÁs REMOTO SE VOLVÍA EL CONOCIMIENTO DEL PASADO QUE PRODUCÍA PARA LAS GENERACIONES QUE SE CONFRONTABAN CON LAS NUEVAS REALIDADES SOCIALES. ${ }^{15}$

Sin embargo, el acceso a "lo real" de la novela quedaba a medias, generándose una paradoja, ya que si bien había una aguda observación de la realidad social, su registro novelado la volvía "ficcional", y para los parámetros de la epistemología occidental de la época -e incluso en gran medida hasta nuestros días-, eso era "imaginario" y no "real" o, en otros términos, se trataba de la oposición entre "realidad" y "ficción”. Y así llegamos al núcleo de la apuesta whiteana expuesta en el libro que nos ocupa, en el cual hace una rectificación a su postura previa -honestidad digna de un intelectual de su altura-. En primer término adopta el término de "escritura literaria" ("literary writing") frente al de "escritura histórica" ("historical writing") para referirse a lo que había reconocido simplemente como "literatura" en general:

La idea de la escritura literaria (opuesta a la "literatura") me permite refinar la DISTINCIÓN ENTRE HISTORIA (o escritura histórica) Y FICCIÓN (o escritura imaginativa), y superar la creencia de que están ENFRENTADAS UNA A LA OTRA COMO ALTERNATIVAS mutuamente opuestas. Sólo si la ficción se identifica con la escritura acerca de seres imaginarios y la literatura se identifica con la ficción, la relación entre historia y literatura debe ser vista como poco más que una oposición entre el MUNDO REAL (pasado

${ }^{15}$ Ibidem, p. I4.

92 / Perla Chinchilla 
y presente) y FANTASÍA, sueños, ensoñaciones, y otras actividades asimismo fantasmáticas (ilusiones, espejismos, fobias y otros). ${ }^{16}$

Con este giro consigue aproximar lo historiográfico y lo literario de otra forma, remontando la idea de que la literatura es sinónimo de "ficción/fantasía” y la historiografía de "historia/ realidad", pues por una parte afirma que

NO TODA ESCRITURA LITERARIA ES FICTICIA, COMO NO TODA ESCRITURA LITERARIA ES NECESARIAMENTE LITERARIA. La biografía y la autobiografía, la escritura de viajes y la escritura antropológica pueden ser "literarias" pero no ficticias, mientras que ciertos tipos de escritos imaginativos, tales como la fantasía científica, la "chick lit", las telenovelas, la publicidad y demás, serán ficticios pero no por fuerza literarios. En otras palabras, algún escrito ficticio es literario en el sentido de que tiene una función poética en su predominio, mientras que otros escritos ficcionales -formulaicos, rebuscados o simplemente algorítmicos- son todo menos literarios porque la función poética falta o es nula. ${ }^{17}$

A partir de este desplazamiento pueden observarse dos consecuencias, a saber: por una parte, la posibilidad de que parte de la "escritura literaria" -la "moderna novela realista" sobre todotenga como referente la "realidad" que sólo se concebía como propia de la "escritura histórica"; al tiempo que esta última se vuelve por necesidad literaria -o sea, pertenece a la "escritura literaria" en general- dada la función poética del lenguaje en el que se inscribe, por otro; ${ }^{18}$ si bien en este caso es cierto que no

${ }^{16}$ Ibidem, p. xii.

${ }^{17}$ Idem.

${ }^{18}$ Idem. "Efectivamente, yo sugeriría en este punto de mi propio discurso que la teoría del acto de hablar de J. L. Austin [...] es o puede con legitimidad ser considerada como una teoría de la función poética del lenguaje (en oposición a sus funciones referenciales, expresivas, conativas, fáticas y metalingüísticas), pues, ¿qué más puede ser la enunciación poética sino un hacer o un realizar 
se trata de lo "artístico"19 en el mismo modo que un "poema, unas memorias o una novela". Es importante resaltar que el uso del concepto de "novela" que White hace aquí es el tradicional, y no el que adquiere con el calificativo de "posmoderna" -que él mismo distinguirá más tarde-, ya que desde el inicio del xix el propósito de la primera era construir un "pasado histórico objetivo", lo cual esta última no se propone. ${ }^{20}$ En pocas palabras, toda historiografía sería "escritura literaria", en tanto que cierto tipo de "novela" sería "históricamente realista".

\section{3) El HISTORICAL PAST Y LA HISTORIOGRAFÍA CIENTÍFICA}

El precio por el abandono de la retórica ha sido, entonces, el del sacrificio de su tradicional papel de guía de la acción social, al situarse en el espacio de lo que Oakeshott -citado por Whitedenomina el historical past. Él lo define como

una construcción teóricamente motivada, QUE SÓLO EXISTE EN LOS LIBROS Y EN LOS ARTÍCULOS PUBLICADOS POR HISTORIADORES PROFESIONALES; está construida como UN FIN EN Sí MISMO, posee poco o nulo valor para la comprensión o LA EXPLICACIÓN DEL PRESENTE, Y no ofrece ORIENTACIONES PARA ACTUAR EN EL PRESENTE O PARA PREVER EL FUTURO. NADIE NUNCA EN REALIDAD VIVIÓ O EXPERIMENTÓ EL PASADO HISTÓRICO PORQUE ÉSTE NO PUDO HABER SIDO APREHENDIDO CON BASE EN LO QUE SEA QUE HAYA SIDO LO QUE LOS AGENTES DEL PASADO CONOCIERON,

algo mediante un modo, o una manera, o un estilo particular de decir algo?" Ibidem, p. 34 .

${ }^{19}$ Aclaro que White no habla de lo "artístico" en sí, y aquí, el término lo uso bajo el concepto de "Arte" de Luhmann. Para él es un subsistema funcionalmente diferenciado, regido por el código Arte/No Arte, por lo cual no puede tener una función fuera de la propia del sistema. Cfr. Niklas Luhmann, El arte de la sociedad.

${ }^{20}$ Cfr. White, The Practical Past, op. cit., pp. xii y ss. 
SUPIERON O IMAGINARON SOBRE SU MUNDO, DURANTE SU PRESENTE. Los historiadores, observando el pasado desde el punto de vista aventajado de un futuro estado de las cosas, pueden apelar a un conocimiento sobre el presente del pasado que ningún agente del pasado en su presente pudo haber poseído. ${ }^{21}$

Sin entrar en la discusión que tal diagnóstico podría generar frente al muy conocido de Koselleck ${ }^{22}$-quien señala que ya al inicio de la Modernidad había un declive del papel de la historia magistra debido a los cambios sociales por ésta generados-, desde la óptica de White pude desprenderse la observación de que al menos dos factores hicieron menos evidente este alejamiento de su antigua función durante el siglo xix. Por un lado, el ya mencionado, sobre la coincidente "neutralidad" y el "empiricismo" de la emergente historiografía científica con la cosmovisión "evolutiva" y "progresista" de la época, misma que confiaba en la ciencia como la guía de la acción que conduciría a la sociedad por el camino del bien. Por otro, las emergentes filosofías de la historia que, aunque repudiadas cada vez más por una escritura de la historia aséptica, ${ }^{23}$ cumplieron por muchas décadas con esa función orientadora. Aquí debemos resaltar que White considera que incluso en ese momento la "filosofía de la historia pertenece a la clase de disciplinas que quieren conferir orden y razón a un 'pasado práctico' más que al 'pasado histórico' construido por historiadores profesionales para la edificación de sus pares en sus distintos campos de estudio". ${ }^{24}$

\footnotetext{
${ }^{21}$ Ibidem, pp. 9-Iо.

${ }^{22}$ Reinhart Koselleck, "Historia magistra vitae: sobre la disolución del topos en el horizonte de la agitada historia moderna”, en Futuro pasado: para una semántica de los tiempos modernos, pp. 4I-66.

23 “[L]a 'filosofía de la historia' del tipo heredado de Comte, Hegel y Marx, y promovida por Spengler, Toynbee y Croce en el tiempo que va entre las dos Guerras Mundiales como mera 'ideología' o como una profecía religiosa que se hace pasar por 'ciencia histórica'". White, The Practical Past, op. cit., p. I7.

${ }^{24}$ Ibidem., pp. I6-I7.
} 
En la base de los límites de la historia ciencia y de la correspondiente construcción del historical past está el concepto de "evento histórico", al que ya también hicimos alguna referencia, y al que dedica todo un capítulo del libro -justamente titulado "The Historical Event"-. Aquí solo señalamos que éste es la piedra angular sobre la que se basa el argumento realista de la historia ciencia, y sobre el que se ha construido este historical past. Por tal, nuestro glosado autor entiende:

cualquier suceso que SE PRESTE A SÍ MISMO A UNA INVESTIGACIÓN CON LAS TÉCNICAS Y LOS PROCEDIMIENTOS vigentes en el gremio de historiadores profesionales. Tal evento puede acontecer en la vida práctica de una determinada sociedad, o de otra clase de grupo, pero en la medida en que puede ser estudiado como "evento histórico", será desplazado fuera de la categoría de los eventos del pasado que pueden ser utilizados para propósitos prácticos y será COLOCADO EN AQUEL "PASADO HISTÓRICO" donde SE HARÁ DE Él SÓLO UN OBJETO DE CONTEMPLACIÓN, más que una herramienta para ser usada en el presente con FINES PRÁCTICOs. ${ }^{25}$

Así objetivado, deberá estar documentado con rigor y no podrá pertenecer al espacio de lo "imaginario". El núcleo de su existencia está en que sea "verdadero", o sea, que en verdad haya existido, o, en los términos de este tipo de visión, que haya sido "real".

Pero, justamente, a esta visión historiográfica Hayden White enfrenta su libro The Practical Past, desde una autorreconocida postura constructivista:

aunque los historiadores profesionales modernos se limiten a las afirmaciones sobre el pasado que pueden derivarse del estudio de documentos, monumentos y otros vestigios de la realidad del pasado, la clase de estudio de dicha evidencia permitida por la

${ }^{25}$ Ibidem, p. 43.

96 / Perla Chinchilla 
profesión histórica es tan ad hoc, meramente de sentido común y fragmentaria, que ni siquiera el criterio de coherencia podría evocarse sin que HAYA DEMASIADAS RESERVAS QUE SEAN DE TIPO Figurativo (y, por ESO, De Factura Ficticia). La idea de que las relaciones entre las cosas (más bien que entre los conceptos) SON LÓGICAMENTE COHERENTES Y, POR TANTO, REFLEJOS DE LA REALIDAD de las cosas al parecer relacionadas de esa manera y de las relaciones entre ellas -todo esto es METAFísicAmente DEMASIADO IDEALISTA COMO PARA SER CREÍBLE EN LA MODERNIDAD-. ${ }^{26}$

Me parece -y hago ya en este punto especial hincapié- que al identificar su postura constructivista colocando el discurso histórico como el resultado de un acceso a la realidad que identifica con una concepción de "ficción" (fiction-making) de una índole distinta -como adelante veremos-, se añade una tuerca más al giro que venimos desentrańando.

4) El PRACTICAL PAST Y LA NOVELA POSMODERNA

A partir del concepto de practical past White hace una crítica de la actual función social de la historia científica, comparándola con su anterior papel de orientadora de la acción. ¿Qué es lo que la ha separado del presente, y por tanto de los problemas "morales y societales" actuales? Su diagnóstico se centra, por una parte, en su limitada posibilidad de representar el acontecer debido a las propias restricciones epistemológicas y metodológicas que provienen de la necesidad de mostrar "fácticamente" lo sucedido para poder demostrar su "verdad". En varias partes del libro refiere que el imperativo de la "verdad" restringe el universo de análisis del historiador, y justo el enfocarse al practical past le

${ }^{26}$ Ibidem, p. xi.

La Historia magistra vitae y el practical past / 97 
es posible mostrar el amplio espectro del "acontecer" al que no tiene acceso la historia científica. El del "PASAdo REPRIMIdo, LA MEMORIA, EL SUEÑO Y EL DESEO”, desde lo más personal, hasta los "grandes programas políticos", pero, desde luego, todo vivido en el presente de los actores sociales. ${ }^{27}$ De estos pasados no se ocupa la historiografía, y no están incluidos en el historical past, en tanto que White nos muestra cómo la novela posmoderna lo hace con gran maestría.

En el siglo xix la "novela histórica" sirvió de espejo a la naciente historia científica, ya que entonces la distinción entre el "pasado real", del que se ocupaba ésta, y "las ficciones" que sobre el pasado elaboraba la literatura, se veía como aproblemática, en tanto que ya en el xx se empezaron a observar dificultades al respecto. Éstas fueron primero develadas por los novelistas, pues justamente ellos, ocupados de su presente, fueron los que comenzaron a denunciar las fracturas y horrores de la Modernidad. White señala con agudeza que "la primera generación de escritores modernistas, representada por Conrad, Proust, Joyce, Eliot, Pound, Woolf, Kafka, Stein, Gide y otros, todos los cuales parecían Haberse OPUESTO A LA 'HISTORIA' COMO CAUSA MÁS QUE COMO UNA SOLUCIÓN AL PROBLEMA de cómo lidiar con un presente oprimido por las supervivencias del pasado". ${ }^{28}$ A esta visión, nos dice, se la ha acusado de ser "un narcisismo presentista", con una percepción desviada del pasado, y un desdén por "la verdad y el hecho", pero con la siguiente generación, la creadora de lo que él denomina "novela posmoderna", las cosas han cambiado: ${ }^{29}$

Pero la REAnimación, en la segunda mitad del siglo xx, del género de novela histórica del temprano siglo XIX (Scott, Manzoni, Dumas, Balzac) suscita la pregunta acerca de su significatiVIDAD IDEOLÓGICA. En otras palabras, al escoger el género de

${ }^{27}$ Ibidem, p. 9.

${ }^{28}$ Ibidem, p. I7.

${ }^{29}$ Ibidem, p. 77.

98 / Perla Chinchilla 
"novela histórica", escritores posmodernistas tan diferentes como Pynchon, Mailer, Capote, DeLillo, Roth, Pat Barker, W. G. Sebald, Coetzee, Grass, Danilo Kiš, Robert Rosenstone, William Gass, y muchos otros, DESAFIARON EL DOGMA QUE HIZO DE LOS “HECHOS HISTÓRICOS" EL ESTÁNDAR MEDIANTE EL CUAL VALORAR EL REALISMO DE CUALQUIER DISCURSO SOBRE EL PASADO O EL PRESENTE REAL. ${ }^{30}$

De hecho, esta novela es la que tiene las herramientas para representar el acontecer de esta sociedad posmoderna -así como del pasado que ésta requiere representar-, mismas con las que no cuenta la escritura profesional de la historia. ${ }^{31}$

¿Cómo ha conseguido este tipo de novela la representación de la realidad contemporánea?, ¿cómo se relaciona nuevamente con la "historia"? y, por último, ¿cómo se vincula con el practical past? White cita a Jameson en su sintético argumento -casi un manifiesto- sobre el asunto:

[L]a novela es el GÉNERO MODERNISTA POLIVALENTE POR EXCELENCIA, el género en el que, a diferencia del romance, el "entramado" muestra la IMPOSIBILIDAD EN LA HISTORIA DE UNA "TRAMA" Simple, DE ALCANCE GLOBAL, COHERENTE y COMPREHENSIVA, O DE UN "Significado" totalizador. Sin duda, la novela modernista -en Woolf, Proust, Mann, Joyce- "iba en busca del espejismo de la unificación que aún compartía con la filosofía”, pero con el advenimiento del posmodernismo (o del modernismo tardío) todo ha cambiado: la novela posmodernista no sólo toma a LA “HISTORIA" COMO SU REFERENTE MANIFIESTO,

\section{${ }^{30}$ Ibidem, pp. 17-1 8.}

31 "Lo que estoy sugiriendo es que las innovaciones del modernismo [...] pueden ofrecer mejores instrumentos para representar eventos modernistas (y eventos premodernistas en los que tenemos intereses típicamente modernistas) que las técnicas por tradición utilizadas para contar historias para la representación de eventos del pasado que, se supone, debían ser cruciales para el desarrollo de la identidad de sus comunidades". Hayden White, "The Modernist Event", p. 82. 
sino que también abandonó la búsqueda de UNA TRAMA O UNA NARRATIVA MAESTRA DE ALCANCE GLOBAL y "eligió acoger LA DISPERSIÓN Y LA MULTIPLICIDAD". ${ }^{32}$

Desde aquí ya se puede empezar a vislumbrar un auténtico programa de cómo la historiografía podría remontar sus limitaciones $^{33}$ y cuestionar su aproximación al historical past a partir de los logros de este tipo de novelas. Aunque de modo muy apretado, se pueden señalar algunos puntos centrales en su propuesta que van en este sentido, y que tocan la posible recuperación de su papel de guía hoy, a saber: el abandono de la narrativa y del personaje/sujeto propio de ésta; la aceptación de la historia del presente, del anacronismo y de la simultaneidad; y en el núcleo de tal propuesta, la transformación de la "verdad" como su objetivo central, a cambio del retorno a la "ética" -su papel de magistra-, sin por ello descuidar lo verdadero, pero de otro modo. Es interesante destacar que White nos hace notar que esta mudanza haría necesario reconocer su inserción -explícita o no- en alguna filosofía de la historia. En cuanto a la propia historiografía, es un hecho que desde la segunda mitad del siglo xx ésta ha revisado, si no todos, al menos los aspectos relativos a la "narrativa" y al "sujeto", como él mismo lo reconoce al referirse a Braudel y sus herederos. ${ }^{34}$ Sin embargo, me parece que debemos recordar que esta revisión historiográfica promovió que la escritura de la historia se ocupara de la "historia de la sociedad" - de las estructuras-y no de las personas en cuanto tales, que es lo propio del practi-

\footnotetext{
${ }^{32}$ Ibidem, p. 96.

33 "La profesionalización de los estudios históricos requirió, en principio al menos, que el pasado fuera estudiado, como se decía, 'por sí mismo' o como una 'cosa en sí misma', sin ningún motivo ulterior más que el deseo por la verdad (del hecho, es verdad, más que de la doctrina) sobre el pasado y sin ninguna inclinación a derivar lecciones del estudio del pasado e importarlas al presente a fin de justificar acciones y programas para el futuro". Ibidem, p. 9.

${ }^{34}$ Cfr. La obra pionera de Fernand Braudel titulada La Méditerranée et le Monde Méditerranéen à l'époque de Philippe II, cuya primera edición se publicó en I 949.
} 
cal past. Si bien se trata de problemas no resueltos, y más bien generadores de posturas diversas dentro de la comunidad de los historiadores, lo que aquí se resalta -lo novedoso que observo en la propuesta whiteana- es que, al postular a la novela posmoderna como la generadora de un cambio paradigmático, se refiere al pasado práctico de las personas, a los sujetos en su individualidad, si bien en una tónica "posmoderna". Y en esta "tónica”, los cambios que se sugieren no sólo tocan el replanteamiento de la relación de la historia ciencia con el presente, sino que cuestionan el modo mismo en que ha constituido el historical past-lo cual se explica al ser ella misma producto de la Modernidad y, de ahí derivada, su construcción de esa propia Modernidad-. ${ }^{35}$

Desde la novela modernista White observa un "trabajo preparatorio" para la disipación del "evento histórico" tal como lo ha concebido la historiografía, a partir de la dislocación de una estricta escritura lineal, la disolución de la separación entre el presente y el pasado, así como la renuncia a una clara distinción entre lo consciente y lo inconsciente. Más que un "repudio", se trata de la liberación del "evento histórico" sujeto a la trama, a través del abandono de la trama misma. "Además, lejos de abandonar

${ }^{35}$ Pregunta por la naturaleza, el significado y la función discursiva del evento histórico: "Me permito enfatizar que por el término 'historia' quiero decir 'el pasado', ciertamente, pero también algo distinto y algo más. Cada individuo y cada grupo tiene un pasado, nada más en virtud de tener una pertenencia genética y cultural de alguna clase. Pero un pasado hecho con pertenencia genética y cultural no es lo mismo que el pasado histórico. En nuestros tiempos, que son los de la modernidad tardía, un pasado en específico histórico es creado por profesionales o por investigadores de alguna manera autorizados de lo que es sólo un pasado virtual, siempre y cuando no haya sido establecido como un pasado en realidad acontecido sobre la base de evidencia de algún tipo específico y autoridad. Este pasado histórico ES UNA CONSTRUCCiÓN HECHA CON LA SELECCIÓN, DESDE UNA AMPLIA GAMA DE TODOS LOS EVENTOS DEL PASAdO HUMANO, DE UN MONTÓN ESPECÍfICO DE ESOS EVENTOS QUE PUEDEN SER ESTABLECIDOS COMO QUE HUBIERAN ACONTECIDO EN TIEMPOS ESPECÍFICOS Y EN LUGARES, Y PUEDEN SER ENCUADRADOS EN RECUENTOS DIACRÓNICAMENTE ORgANiZAdos DE LA AUTOCONSTITUCIÓN DE UN GRUPO EN EL TIEMPO”. White, The Practical Past, op. cit., p. 42. 
la realidad por la fantasía, el modernismo muestra qué tanto lo fantástico está contenido en 'lo real'”. ${ }^{36} \mathrm{~A}$ medida que se borra la línea entre ficción y realidad, la novela modernista se distancia del historical past y se aproxima al practical past. A partir de ahí, la novela posmoderna ha retomado cada vez más en su escritura la problemática de éste, y a través de ello, de alguna forma, pega en el núcleo mismo de la historicidad. A partir del concepto de "evento modernista" ${ }^{37}$-como lo denomina-, White trastoca la propia noción de "evento histórico", no sólo en términos de su registro, sino, más radicalmente, en cuanto a su "referente", al ser su "sustancia" la "idea historizada del trauma" -el "evento traumático"-, desde el cual se desmonta el primero. ${ }^{38} \mathrm{Y}$ es justo en esta reconfiguración de la concepción del "evento histórico" donde la propuesta de White vuelve visible y plausible una historia magistra vitae hoy.

Hay que resaltar que el cambio que White propone a la historiografía es de una audacia y novedad únicas, ya que no se trata de una propuesta teórica, sino de ejemplos concretos que este tipo de novela lleva a cabo en sus textos, mismos que indican por dónde habría de transitar la transformación paradigmática de la escritura histórica. En la próxima sección se presentan algunos casos de cómo esos novelistas han resuelto las mutaciones solicitadas por el mundo actual.

\footnotetext{
${ }^{36}$ Ibidem, p. 57.

${ }^{37}$ Vid. supra, n. 3 I.

38 “[I] dentificar el nuevo 'contenido' o fenómeno para cuya representación la nueva clase de escritura es considerada como adecuada. Ya he aludido al 'evento modernista' como dicho contenido, fenómeno o referente. Ahora avanzaré y sugeriré que la 'substancia' del 'contenido' de este nuevo tipo de evento se ofrece en la idea historiotetizada del 'trauma'. No puedo terminar este recuento del evento histórico sin referir a lo que, a menudo, es considerado como el nuevo tipo de evento histórico, lo que es denominado 'el evento traumático"'. White, “The Modernist Event", op. cit., p. 58.
} 
Esta pequeña y experimental muestra se ha realizado a partir de dos novelas citadas por White en el texto The Practical Past, y una de Norman Mailer, a quien también refiere. Es importante destacar que los aspectos resaltados, así como la seleccción y conexión con los párrafos que ejemplifican el caso, es mi propuesta interpretativa, ya que White no entra en detalle en su texto. Se trata de un camino inicial que podría proseguirse en muchos sentidos, pero en este caso la pretensión es aproximarse a la viabilidad de la historia magistra vitae hoy. O sea, de la posibilidad de llegar a orientar (o a tener conciencia de la no-orientación) la vida cotidiana de los millones de "ese/os" "yo/es" frente a la distante Historia con mayúscula, tal como nos los presenta Don DeLillo en Submundo:

LA Historia ES EL RESUltado DE ANHELOS EN GRAN ESCALA. Aquí no hay más que un CHIQUILlo que alimenta una aspiración localizada, pero forma parte de una MUCHEdumbre en desarrollo, de miles de seres anónimos que brotan de los autobuses y los trenes, de gente que avanza a trompicones formando estrechas hileras sobre el puente giratorio que atraviesa el río; PERSONAS QUE NO REPRESENTAN UNA MIGRACIÓN NI UNA REVOLUCIÓN NI UNA VASTA AGITACIÓN DEL ALMA PERO QUE TRAEN CONSIGO EL CALOR CORPORAL DE LA GRAN CIUDAD Y SUS PROPIOS ENSUEÑOS Y DESESPERACIONES, ese algo invisible que domina una época... hombres con sombreros de fieltro y marineros de permiso, el distraído revoltijo de sus pensamientos, camino del partido [de beisbol]. ${ }^{39}$

${ }^{39}$ Don DeLillo, Submundo, p. 3. 
Esta cuestión me interesa por la creencia que hay entre algunos historiadores de que la historia y todos los predicados que se hacen sobre la historia o sobre el pasado deben "DECIR LA VERDAD". Además, es un principio de los predicados historiográficos que no deben "mentir", "distorsionar" o "representar falsamente", o denegar, omitir, negar, o desautorizar aquellos "HЕCHOs” que han sido establecidos en relación con algún aspecto de la "REALIDAD" del pasado. ${ }^{40}$

Ante la reiterada insistencia de White respecto a que la mayor limitante del referente histórico está en la concepción de lo real del pasado, con la cual la disciplina fue constituyendo el historical past, él afirma que el "modernismo literario" se distancia del "realismo tradicional" al asumir al practical past como su "referente principal”. Conectado con ello, está la dilución de la distinción entre pasado y presente, la cual la historiografía científica no ha asumido, incluso en muchas de las propuestas de la "historia del tiempo presente". ${ }^{41}$ Seguir asumiendo una distinción tajante le resta al evento en general su "frescura" y "perceptibilidad", y de ahí la plausibilidad de ser representado en términos de una causalidad lineal, ${ }^{42}$ lo cual no sería un cambio menor para las explicaciones realizadas desde la historia.

Veamos un ejemplo de esta última imposibilidad:

Quizá la historia en este siglo, pensó Eigenvalue, presenta en la estructura de su tejido unos pliegues de forma tal que si está situado, como parecía estarlo Stencil, en el fondo de uno DE LOS PLIEGUES, RESULTA IMPOSIBLE DETERMINAR LA URDIMBRE, TRAMA o Dibujo DE CUALQUiER OTRO PUNTO. Sin embargo, en virtud de

${ }^{40}$ White, The Practical Past, op. cit., p. 29.

${ }^{41}$ En París, en el Institut d"Histoire du Temps Présent se ocupan de la reflexión sobre los múltiples problemas de hacer "historia del tiempo presente".

${ }^{42}$ White, The Practical Past, op. cit., p. 78. 
la existencia de un pliegue, se establece la hipótesis de que existen otros, compartimentados en forma de ciclos sinuosos CADA UNO DE LOS CUALES LLEGA A ASUMIR MAYOR IMPORTANCIA QUE LA PROPIA ONDULACIÓN Y DESTRUYE CUALQUIER TIPO DE CONTINUIDAD. Así ocurre que nos encanten los divertidos automóviles de los años treinta, las curiosas modas de los veinte, los peculiares hábitos morales de nuestros abuelos. Ponemos en escena y acudimos a ver comedias musicales sobre ellos y leemos hasta hacernos una falsa memoria, una pseudonostalgia de lo que fueron. Estamos, EN CONSECUENCIA, PERDIDOS PARA CUALQUIER SENTIDO DE UNA TRADICIÓn CONTINUA. Quizá si viviéramos en una cresta las cosas serían diferentes. Podríamos, cuando menos, ver. ${ }^{43}$

El caso extremo es "el evento modernista", respecto al cual incluso se cuestiona la posibilidad misma de su representación. Éste es el tipo de acontecer más relevante para nuestro glosado autor y para la novela posmoderna, dado el problema ético que lo atraviesa. "Lo que he llamado eventos modernistas están 'sobredeterminados' de tal manera que no pueden nunca ser entramados de acuerdo a patrones usados desde tiempos antiguos para conferir sentido a los eventos". ${ }^{44}$ Un magnífico ejemplo de esta dificultad -que conlleva la de nombrarlo y darle sentido- se encuentra en Los desnudos y los muertos, novela que se desarrolla en Japón durante la intervención norteamericana en la Segunda Guerra Mundial:

Para calmar sus tensos nervios, dirigió su atención a las operaciones de limpieza.

Sexto día:

347 japoneses - I norteamericano.

Noveno día:

502 japoneses -4 norteamericanos.

${ }^{43}$ Thomas Pynchon, V., pp. I66-I67.

${ }^{44}$ White, The Practical Past, op. cit., p. 78. 
Las patrullas se internaban detrás de las líneas de los japoneses. Recorrían en oleadas los pasajes del laberinto, abrían senderos en la selva para descubrir a algunos sobrevivientes que se hubieran refugiado en la jungla. Desde el alba hasta el anochecer las patrullas recorrían la selva en busca del enemigo.

La operación era sencilla, un mero juego. Después de varios meses de guardia nocturna, de patrullas expuestas a emboscadas continuas, las operaciones de limpieza eran relativamente agradables, casi divertidas. La matanza adquirió una dimensión irreal, les incomodaba menos que el rastreo de los últimos reductos japoneses.

Algunas acciones eran mera rutina. Los japoneses habían establecido varios hospitales pequeńos en las últimas semanas de la campaña, y al retirarse habían matado a muchos de los heridos graves. Cuando llegaban los norteamericanos, remataban a todos los heridos que quedaban, rompiéndoles el cráneo a culatazos, o disparándoles a quemarropa.

Pero había otras maneras más personales de proceder. Una patrulla descubrió al amanecer a cuatro soldados japoneses que estaban durmiendo en un sendero, cubiertos con sus capotes impermeables. El jefe de la columna se detuvo, recogió unas piedras y las lanzó al aire. Las piedras cayeron sobre el primer soldado dormido produciendo un ruido sordo, parecido al del granizo. El soldado se despertó lentamente, se desperezó, bostezó, grunó poco, se aclaró la garganta y estiró los miembros, haciendo ruidos inarticulados de los hombres que se despiertan temprano. Después asomó la cabeza bajo el capote. El jefe de la patrulla esperó a que el japonés lo viera y entonces, en el momento en que éste iba a gritar, el norteamericano lo ametralló. Después, apuntando el arma al centro del sendero, hizo una serie de agujeritos en la tela impermeable. Sólo un japonés quedó con vida. Una pierna extendida fuera del capote se sacudía convulsivamente, como un animal agonizante. Otro soldado se aproximó, tanteó el cuerpo del japonés con el cañón del fusil, encontró la cabeza e hizo fuego. ${ }^{45}$

${ }^{45}$ Norman Mailer, Los desnudos y los muertos, pp. 722-723.

106 / Perla Chinchilla 
Para dar cuenta de un tal "evento" White trabaja con la latencia, cuya posible emergencia permite suponer que en algún punto podrá nombrarse y conseguir sentido. Ello, no obstante -aclara- sólo podría lograrse en un evento posterior. Pero no cualquiera, sino aquel que le permita -sin importar lo "obscura" y "enmascarada" que sea esta operación- ser representado y adquirir el sentido que yacía latente en el primero, y ahora se hace manifiesto en el segundo. ${ }^{46}$ Mailer, justamente, hace un guiño hacia esa posibilidad, cuando, al referirse al "indecible" evento arriba citado, escribe: "Pocos norteamericanos estaban en condiciones de entender las CONTRADICCIONES DE LA ÉPOCA QUE SE AVECINABA. El camino del poder omnímodo IBA A ESCONDERSE BAJO LA MÁSCARA del liberalismo conservador. Los reaccionarios y aislacionistas iban a perder el tren, e iban a causar muchas molestias, como si fueran alguien". ${ }^{47}$ Cabe hacer notar que, con este pasaje abrupto ¡concluye la novela de más de 700 páginas! ¡Como si retara al historiador -tal como White lo propone- para que después nombre y otorgue sentido al "evento traumático"!

Frente a la supuesta garantía que la fuente le otorga a la historiografía científica, estas novelas muestran cómo el pasado oculta sus "secretos", incluso hasta la destrucción de las fuentes. En medio de todo ello, la veracidad de lo ocurrido se vuelve no sólo difícil de discernir, sino un asunto secundario. Un buena muestra de ello es un pasaje de $V$., en el que Thomas Pynchon narra "unas

46 "Freud no rechaza o cuestiona la idea histórica convencional de que un evento en un tiempo y espacio determinado 'se extiende', por así decirlo, tanto en el tiempo como en el espacio, con lo que se produciría el tratamiento de otros eventos como 'efectos' de una 'causa' previa. Pero él sí postula otra clase de evento, cuya verdadera naturaleza y cuyos efectos se entierran en la memoria colectiva, yacen latentes a partir de entonces, durante un rango de tiempo indeterminado, y luego, como respuesta a algún evento posterior de efectos similarmente invasivos, resurgen en una forma que al mismo tiempo revela y oculta su prototipo remoto. Tal evento, el evento traumático, tiene la estructura del modelo del cumplimiento de figura de la teodicea hebrea $y$ cristiana”. White, The Practical Past, op. cit., pp. 6I-62.

${ }^{47}$ Mailer, Los desnudos, op. cit., pp. 722-723. 
historias subterráneas". Son tales -subterráneas- en dos sentidos, tanto porque aparecen en las cloacas de Nueva York, como porque han sido ocultadas debido a su carácter "heterodoxo", ya que refieren cómo un párroco, al día siguiente de haber ascendido Roosevelt al poder, ingresó a las alcantarillas con la intención de echar agua bendita a las aguas y de convertir a las ratas. De esta historia queda un diario del párroco en el Vaticano -inaccesible para el público-, así como relatos de algunos trabajadores de aquel tiempo que aún viven en el presente del también trabajador Profane, quien ingresa en las cloacas y da cuenta de esta historia subterránea. Al respecto, Pynchon escribió:

Estas historias, por la época en que las oyó Profane [20 años después] eran considerablemente más apócrifas y más fantásticas de lo que autorizaba la crónica en sí. En ningún momento, en los veinte años y pico que hacía desde que la leyenda se había ido transmitiendo, se le ocurrió a nadie poner en tela de juicio la cordura del viejo sacerdote. Las historias de alcantarilla son así. Simplemente existen. LA VERACIDAD O LA FALSEDAD NO SON CATEGORÍAS QUE LES SEAN APLICABLES. ${ }^{48}$

El segundo ejemplo, proveniente de Submundo, expone cómo "el pasado oculta sus secretos":

Le digo a Viktor que existe una curiosa conexión entre los armamentos y los desechos. Ignoro exactamente en qué consiste. Él sonríe y pone los pies sobre el banco, como una gárgola agachada. Dice que quizá los unos sean los mellizos místicos de los otros. Le gusta la idea. Dice que LOS DESECHOS SON LOS MELLIZOS DIABÓLICos. Porque los Desechos CONSTITUYen la historia SECRETA, LA INFRAHISTORIA, el modo en que los arqueólogos excavan la historia de las culturas tempranas, montones de huesos y herramientas rotas de todas clases, literalmente de debajo de la tierra. ${ }^{49}$

\footnotetext{
${ }^{48}$ Pynchon, V., op. cit., p. I 28.

${ }^{49}$ DeLillo, Submarino, op. cit., pp. 5 I6-5 I 7 .
}

108 / Perla Chinchilla 
Acorde con estas transformaciones, la novela posmoderna trastoca la temporalidad lineal de la escritura, y "descubre la multiestratificación de la experiencia del tiempo y de la temporalidad, y busca presentarla de tal manera que destroce nuestra confianza en la temporalidad narrativísticamente ordenada de la leyenda popular, de la fábula y de la 'historia".${ }^{50}$ La complejidad temporal de estas novelas muestra al historiador el reto que representa aproximarse a la problemática del lector contemporáneo respecto a su propio pasado y por tanto a su identidad. Un par de ejemplos al respecto; el primero, de $V$. de Pynchon:

Podemos justificar cualquier apología simplemente llamando a la vida rechazo sucesivo de personalidades. Ninguna apología es otra cosa que una novela - una semificción- en la que ToDAS LAS IDENTIDADES SUCESIVAS ADOPTADAS Y RECHAZADAS POR EL ESCRITOR COMO FUNCIÓN DEL TIEMPO LINEAL, SE TRATAN COMO PERSONAJES INDEPENDIENTES. El PROPIO HeCHO DE ESCRIBIR CONSTITUYE OtRo RECHAZO, Otro "PERSONAJE" aŃadido AL PASADO. Vendemos efectivamente el alma: entregándola a la historia a pequeńos plazos. No es tanto para pagar unos ojos lo suficientemente claros como para ver más allá de LA FICCIÓN DE LA CONTINUIDAD, LA FICCIÓN DE LA CAUSA Y EL EFECTO, LA FICCIÓN DE UNA HISTORIA HUMANIZADA DOTADA DE “RAZÓN" ${ }^{51}$

Don DeLillo ironiza la pretensión del orden que supone la historia cuando se compara con la experiencia cotidiana: "Y a mí me gustaba el modo que tenía la historia de no descontrolarse. Segregaban historia visible. LA ENJAULABAN, LA CONSOLIDABAN Y LA BRONCEABAN, LA EXHIBÍAN CUIDADOSAMENTE EN SU RELICARIO EN MUSEOS Y PLAZAS Y PARQUES CONMEMORATIVOS. El resto era geografía, todo espacio y luz y sombra y un opresivo calor inenarrable". ${ }^{52}$

${ }^{50}$ White, The Practical Past, op. cit., p. 78.

${ }^{51}$ Pynchon, V., op. cit., p. 325.

${ }^{52}$ DeLillo, Submarino, op. cit., pp. 54-55.

La Historia magistra vitae y el practical past / 109 
A partir del "evento modernista", la novela posmoderna no sólo se coloca en el punto extremo de la dificultad de representar lo acontecido, sino que cuestiona los propios "acontecimientos (facts)" con los que la historia construye su discurso:

Concedamos que haya EVENTOS y que haya ACONTECIMIENTos. Concedamos también que haya series de eventos y estructuras de eventos que pueden ser factualizados, lo que quiere decir datados, ubicados, descritos, clasificados [...] Pero esta manera de pensar la historia -como una agregación de hechos- hace inevitable la pregunta por el eSTATUS DE AQUeLLOS "EVENTOS" QUE SON EL CONTENIDO, EL REFERENTE O LA CONDICIÓN NECESARIA DE LOS ACONTECIMIENTOS. ${ }^{53}$

Se abre así la pregunta por los "eventos" de los que se componen los "acontecimientos históricos". Un nuevo paradigma historiográfico no nada más ha de replantearse la posibilidad de establecer lo traumático como "evento", ${ }^{54}$ sino la viabilidad misma de que los habitantes del practical past podamos conectar nuestras vidas con las construcciones factuales historiográficas: "las contradicciones sociales de las sociedades capitalistas son múltiples y ubicuas, determinadas por fuerzas impersonales, abstractas y globales en su género, por lo que están 'sobredeterminadas' al grado de que el individuo debe sentirse radicalmente incapaz de conceptualizarlas, y mucho menos invocarlas en la vida cotidiana" ${ }^{55}$ Este género novelístico muestra con lujo de ejemplos este diagnóstico:

${ }^{53}$ White, The Practical Past, op. cit., p. 46.

54 "En la mayor parte de estas discusiones, el que un evento haya sucedido no tiene que ser establecido. Lo QUe sí ES UNA PREGUNTA ES LA NATURALEZA DEL EVENTO, SU RELATIVA NOVEDAD, el alcance y la intensidad de su impacto y su significado o lo que revela acerca de la sociedad en que tuvo lugar”. Ibidem, p. 46. "Mi sugerencia ha sido que no podemos establecer, sobre la base de ningún recuento estrictamente factual, si el Holocausto fue un evento nuevo, un nuevo tipo de evento, o tan sólo un tipo antiguo de evento con un rostro diferente". Ibidem, p. 38.

${ }^{55}$ Ibidem, pp. 95-96. 
La Marina abordó ayer un buque en plena línea de cuarentena. El primero que abordan. Un destacamento armado. Podéis apostar a que allí hubo tensión, tíos. Resultó QUE EL BUQUe NO LLEVABa Misiles. LleVABa PIEZAS DE REPUESTO PARA CAMIONES Y PAPEL HIGIÉNICO. ¿Lo veis? Ahí lo tenéis: la vida normal y corriente intentando reafirmarse de nuevo. Tal es el significado secreto de esta semana. La historia secreta que nunca aparece en las crónicas escritas de la época ni en las declaraciones públicas de los poderosos. Esas bombas y esos misiles tan bonitos. Esos aviones y esos submarinos. ¿Alguna vez habíais visto algo tan maravilloso? Las armas cuentan con los mejores ingenieros y obtienen los nombres más poéticos. ENTRETANTO, Un Granjero CUbano CASCARRABIAS ESTÁ AGUARDANDO A QUE LE ENVÍEN UN CARBURADOR PARA SU DESVENCIJADO TRACTOR. Y, ENTRETANTO, HA TENIDO QUE LIMPIARSE EL CULO CON LA COSECHA DE LEChuga. No hacen más QUe ReCordarle QUe tiene QUE SER PACIENTE, Sí, MIENTRAS ELLOS SOLUCIONAN SUS RELACIONES A ALTO NIVEL. ${ }^{56}$

Para mostrar las insuperables dificultades de darle sentido, orden y continuidad a una realidad compleja, incoherente y discontinua, esta literatura "revoluciona" el discurso "deconstruyendo el mito del narrador omnisciente (homérico) que presupone que 'él' sabe todo lo que vale la pena saber sobre el mundo que describe, que sabe que sabe y que es capaz de reproducir miméticamente tanto el mundo como su propio pensamiento sobre éste sin errores y distorsiones significativas". ${ }^{57}$ Tal es el caso de las tres novelas analizadas, las cuales inician y concluyen en forma abrupta, y cuya indiscernible "trama" se le escapa a menudo a una multitud de narradores.

${ }^{56}$ DeLillo, Submarino, op. cit., p. 390.

${ }^{57}$ White, The Practical Past, op. cit., p. 78. 


\section{b) La narración como forma de representación del pasado}

White asienta que la novela posmoderna no sólo tomó a la "historia" como su "referente manfiesto", sino que a la vez dejó de buscar "an overarching plot" o una "master-narrative" propia de la historiografía tradicional. ${ }^{58}$ ¿Por qué? Más allá de la pretendida eliminación de la narrativa y del personaje que la propia historiografía contemporánea ha llevado a cabo de alguna u otra forma, este tipo de novela exhibe su radical imposibilidad, pero -como ya hemos destacado- ahora para dar cuenta de la experiencia de los sujetos y no de las estructuras, hacia las que se encaminó en su momento la historia social a la Braudel. Ello frente a la inexistencia de la coherencia, de la causalidad lineal, del no dejar cabos sueltos, siendo la pretensión contraria incluso ofensiva frente a eventos traumáticos como el Holocausto, que han de percibirse como más "complicados" y difíciles de "comprender" "que cualquier tipo de historia tradicional o tratamiento dramático podría volver creíble". ${ }^{59}$ Si todavía la novela modernista pretendía el "espejismo de la unidad", la posmoderna muestra la inviabilidad de un sentido único y omniabarcante. Así, el desarrollo de estas novelas le presenta a la historia caminos alternos para conseguir representar esta evasiva realidad que se relaciona más con la vida cotidiana de los habitantes en su presente y su necesidad de saber cómo orientarse en medio de lo intransparente, dando lugar a la emergencia de lo latente. Estos novelistas se ocupan de explicitar al máximo tal complejidad. Me parece que en el siguiente párrafo de Submundo se muestra de un modo magistral cómo lo latente es lo que posibilita la vida:

La civilización no había surgido y florecido mientras los hombres tallaban escenas de caza en verjas de bronce o susurraban filosofía bajo las estrellas, con la basura como una ramificación fétida que

\footnotetext{
${ }^{58}$ Ibidem, p. 96.

${ }^{59}$ Ibidem, p. 82.
}

I 12 / Perla Chinchilla 
barres y olvidas. No, LA BASURA HABÍA FLORECIDO EN PRIMER LUGAR, INCITANDO A LA GENTE A CONSTRUIR UNA CIVILIZACIÓN COMO RESPUESTA, como autodefensa. Teníamos que encontrar modos de eliminar nuestros desechos, de utilizar lo que no podíamos eliminar, de reprocesar lo que no podíamos aprovechar. La basura se defendía. Se acumulaba y se extendía. Y nos forzaba a desarrollar la lógica y el rigor que nos conduciría a sistemáticas investigaciones de la realidad, a la ciencia, el arte, la música y las matemáticas. ${ }^{60}$

El producto coherente que se genera en una narrativa que ordena la temporalidad en forma secuencial, choca con la experiencia cotidiana de la misma, alejando al lector tanto de su practical past-que no lo valora-, como del historical past construido por la historiografía -que le resulta ajeno-. Un ejemplo de Submundo nos muestra la doble exclusión de ambos pasados:

¿Y qué recuerdas, después de todo, cuando todos se han marchado a casa y las calles están vacías de devoción y de esperanza, barridas por el viento del río? ¿Son tus RECUERDOS ESCASOS Y AMARGOS Y TE AVERGÜENZAN con su mentira fundamental: todo matices y sombras imaginarias? ¿ $\mathrm{O}$ aún permanece el poder trascendental, la sensación de un evento que ha transgredido las fuerzas naturales, de algo sagrado que palpita en el cálido horizonte, de la visión que ansías porque necesitas una señal para enfrentarte a tus dudas? ${ }^{31}$

\section{c) El "sujeto" del que da cuenta la narrativa histórica}

"La invención de una historiografía sin sujetos y sin tramas en el siglo $\mathrm{xx}$ ha demostrado con amplitud que la investigación $\mathrm{y}$ la escritura histórica moderna podrían existir sin las nociones de personaje y de trama”. ${ }^{62}$ Observo dos consecuencias ante la acepta-

${ }^{60}$ DeLillo, Submarino, op. cit., p. I 84 .

${ }^{61}$ Ibidem, p. 540.

${ }^{62}$ White, "The Modernist Event", op. cit., pp. I7-I 8. 
ción o el rechazo de ello por la historiografía, mismas que la novela posmoderna le haría notar. Si va en contra de esta afirmación, y continúa aceptando que hay un "sujeto" y una "narrativa" -como efectivamente se hace hoy por hoy todavía en buena medida-, este sujeto y su trama no pueden seguir en la línea tradicional de la narrativa. Pero si va a su favor, y elimina sujeto y narrativa, se aleja del practical past. Es este tipo de novela la que le propone cómo poder aproximarse a tal problemática de otra forma.

Así, en este escenario novelístico el "personaje" (character) tal como ha funcionado en la narrativa tradicional, desaparece. Dicho desvanecimiento se da en al menos dos formas. Por una parte, en cuanto a la dificultad de dar sentido a su presente en función de su pasado, y por tanto el impedimento para contar con una identidad. Un ejemplo de Pynchon en su $V$. nos lo denota: "la memoria es traicionera: dora, altera. La palabra es, en triste rigor, carente de sentido, ya que se basa en el falso supuesto de que LA IDENTIDAD ES ÚNICA, EL ALMA CONTINUA. Un hombre no tiene más derecho a promulgar como verdad ninguna automemoria" ${ }^{63}$

De hecho, hay casos - nos dice White- como el de Austerlitz de W. G. Sebald, en los que la noción misma de personaje "explota en pedazos y en fragmentos de 'hombres sin propiedades". ${ }^{64}$ Todo ello con las consecuencias de los escollos que se presentan para fincar la responsabilidad moral en los actores sociales. Esto, me parece, sería la segunda consecuencia -y para nuestro tema de la historia magistra, la más relevante- de esta disolución del personaje. Un par de muestras más del mismo texto de Pynchon:

No andamos juntos, Stencil, nuestros yos separados no andan juntos como quíntuples o más, siameses. Dios sabe cuántos STENCILs han ido en busca de V. por todo el mundo. ${ }^{65}$

${ }^{63}$ Pynchon, V., op. cit., p. 326.

${ }^{64}$ White, The Practical Past, op. cit., p. 5.

${ }^{65}$ Pynchon, V., op. cit., p. 476.

I 4 / Perla Chinchilla 
La dificultad residía en que Stencil poseía todas LaS IDENTIDADES QUE LE PERMITIERAN DESENVOLVERSE CONVENIENTEMENTE EN EL MOMENTO PRECISO: era meramente "El que busca a $V$." (y CUALESQUIERA PERSONIFICACIONES QUE ELLO PUDIERA SIGNIFICAR), y ella no era más su propia identidad que la de Eigenvalue, el dentista del alma, o cualquier otro momento de la Dotación. ${ }^{66}$

Sobre ese "hombre sin propiedades", inmerso en un mundo -en una estructura- que les ajeno y distante, está este puntual ejemplo en $V$ :

LA GENTE LEÍA LAS NOTICIAS QUE QUERÍA Y CADA UNO CONSTRUÍA, DE ACUERDO CON LA INFORMACIÓN, SU PROPIA MADRIGUERA DE RATAS Y PRIVADO CONCEJO CON LOS JIRONES Y PAJITAS DE LA HISTORIa. Sólo en la ciudad de Nueva York había, haciendo una estimación aproximada, cinco millones de estas madrigueras, hogares de rata o concejos particulares diferentes. Sabe Dios lo que ocurría en la mente de los ministros, los jefes de Estado y los funcionarios públicos de las capitales del mundo. SIN DUDA SUS VERSIONES PARTICULARES DE LA HISTORIA SE TRASLUCIRÍAN EN sus ACTOS. Si entre ellos se daba la tipología normal, ciertamente así debía ser. ${ }^{67}$

6) UNAS NOTAS SOBRE LA "FICCIÓN"

Se trata, es cierto, del núcleo de la propuesta de White desde su primera Metahistory, pero aquí sólo observo, breve y tangencialmente, un aspecto del problema de la ficción en relación con la historia maestra de vida. Y no es gratuito que justo en el texto The Practical Past reelabore su propuesta respecto a la ficción, cuando ha de darle carácter de "realidad" a los acontecimientos que en su

\footnotetext{
${ }^{66}$ Ibidem, p. 240.

${ }^{67}$ Idem.
} 
seno discurren. De hecho, el epígrafe de su artículo "The Practical Past" es la sentencia de Michel de Certeau: "la ficción es el otro reprimido de la historia" ${ }^{68}$

Ya en el primer apartado de este artículo se mencionó la nueva distinción que nuestro autor lleva a cabo, considerando que el acceso a la "realidad del pasado" no es facultad exclusiva de la historiografía, sino también -entre otros- de una parte de la literatura, muy en especial de la novela posmoderna. Me parece que, al menos en este texto, presenta dos concepciones sobre "ficción", una de las cuales afecta de manera más directa la posibilidad de una nueva historia magistra.

Por una parte -como ya se señaló-, no toda "ficción" es literatura, en tanto que "no toda escritura ficcional es necesariamente literaria", y ello se debe a la "función poética del lenguaje"; en este caso la "ficción" se concibe con una función poética. ${ }^{69}$ Pero en otro lugar White señala, al referirse a la autocorrección de su postura previa: "Esto era confuso porque yo había fallado en aclarar que por el término 'ficción' tenía en mente la concepción de Jeremy Bentham al respecto, COMO UNA CLASE DE INVENCIÓN O CONSTRUCCIÓN BASADA EN HIPÓTESIS MÁS QUE EN UNA MANERA DE ESCRIBIR O DE PENSAR CENTRADA EN PURAS ENTIDADES IMAGINARIAS O FANTÁSTICAS".$^{70}$ Así, en este sentido, la ficción sería una "construcción hipotética" que no tiene que ver con lo imaginario o fantástico en cuanto a "irreal". En este mismo sentido, pro-

${ }^{68}$ Cfr. Michel de Certeau, Heterologies: Discourse on the Other, p. 29, apud Hayden White, "The Practical Past", p. Io.

"La apuesta de Certeau por el relato y la ficción no supone una indiferencia respecto a los asuntos de índole factual o veritativa, una suerte de neutralización de la ciencia histórica en nombre de lo meramente lingüístico o narrativo. Habría un intento, por el contrario, de reorientar la relación entre la singularidad inasible del evento (polo de la ficción) y la estructura que lo dota de significado (polo científico)". Rodrigo Castro Orellana, "Michel de Certeau: Historia y Ficción", p. I 24.

${ }^{69}$ Vid. supra, n. I3.

${ }^{70}$ White, The Practical Past, op. cit., p. xii. 
pone remontar el concepto de lo "fáctico" como algo más que su oposición con lo "ficticio". Al referirse al personaje "histórico" de Margaret Garner en la novela Beloved de Morrison, y preguntarse:

¿Esto podría significar que Toni Morrison, al inventar los pensamientos de Margaret Garner, está efectivamente ficcionalizándolos? [...] el hecho es que no hay nada en esta caracterización de su heroína que esté en desacuerdo con lo que es conocido acerca de la "Margaret Garner histórica". ¿DE QUÉ CLASE DE FICCIÓN -UNA FICCIÓN QUE NO ESTÉ, LO ABSOLUTO, EN DESACUERDO CON LOS DATOS CONOCIDOS- PODRÍA TRATARSE? ${ }^{\text {?1 }}$

Aquí parece hacer alusión justo a esa "ficción hipotética" que él describe, y al referirla a lo "realmente acontecido" enroca esta operación con la que la historiografía lleva a cabo cuando supone, articula, interpola, etc., aproximándose a la propuesta de de Certeau. De hecho señala que éste es un caso en el que "la oposición del hecho contra la ficción obscurece más que ilumina”, y que

cuando se trata de lidiar con aquellos aspectos de la realidad que nos obligan a CUESTIONAR LA REALIDAD o, inclusive, la posibilidad de nuestros ideales de la humanidad -como en la esclavitud estadounidense o en el Holocausto-, el escritor interesado en enfrentar de modo directo las problemáticas éticas (la pregunta: ¿qué debería hacer?) involucradas en la consideración de dichos fenómenos podrían perfectamente asumir el papel de ACTUAR $E N$ LA ESCRITURA EL TIPO DE ACCIÓN QUE SE PRESENTA COMO UN EVENTO. $^{72}$

Y ello, sobre todo, en casos en particular ominosos, como es el de la esclavitud aquí tratado, en los que-como en los ejemplos de las novelas antes expuestos- los "eventos" no se documentan, ya

\footnotetext{
${ }^{71}$ Ibidem, p. 24.

${ }^{72}$ Idem.
} 
por su latencia, ya por estar incluso "deliberadamente enterrados" -y aquí un especial hincapié- "no menos que por HISTORIADORES que SE LIMitan al recuento de LOS Hechos DE LA MATERIA". ${ }^{73}$ La "imaginación poética" accede a "fantasmas vocales" de formas "que el historiógrafo nunca se le puede permitir imaginar". ${ }^{74}$

Es cierto que si bien al tocar en este libro el problema de la referencia a lo "real" que por tradición ha supuesto la historiografía, menciona lo "conjetural" o "inferencial" de este conocimiento, y de ahí su necesaria "ficcionalidad" - en el sentido hipotético-, o sea "una construcción o conjetura sobre 'qué tal vez sucedió” o pudo haber sucedido en algún momento y en algún lugar, en el presente, en el pasado o, en efecto, incluso, en el futuro", y aclara que la "defensa de esta posición requeriría de INCURSIONES EN LA ONTOLOGÍA Y EN LA EPISTEMOLOGÍA, POR NO HABLAR DE LA ÉTICA Y DE LA ESTÉTICA DE LA ESCRITURA HISTÓRICA PARA LO QUE AHORA NO ES LA OCASión". ${ }^{75}$ Ante esto, aquí sólo queda "inferir" que si diera un paso más por esta vía, el nuevo paradigma que recomienda a la "historia profesional" tendría que ir en el sentido de este segunda acepción de "ficción", pues ella sería la puerta para poder entrar en la ejemplaridad de la novela posmoderna que él recomienda, o al menos yo no veo otro punto de acceso al practical past, mismo que no deja la huella documental de modo tradicional requerida por ella.

En este ámbito, a modo de un breve excurso, pretendo fortalecer esta idea a partir del concepto de "ficción" que ha elaborado hace poco Elena Esposito, quien atisba que en la Modernidad temprana la "franca necesidad de marcar los límites de la realidad [de los autores del Renacimiento] puede interpretarse por ello como un síntoma de que el asunto del realismo se tornaba cada vez más problemático". ${ }^{76}$ Sobre este diagnóstico, y la creciente

\footnotetext{
${ }^{73}$ Idem.

${ }^{74}$ Idem.

${ }^{75}$ Ibidem, p. x.

${ }^{76}$ Elena Esposito, Die Fiktion der wahrscheinlichen Realität, p. I 5. "La realidad
} 
distinción entre "realidad" y "realismo", le atribuye a la novela en general, y después a la "novela realista", la mostración de una nueva realidad, que justamente tiene la función de denotar la intransparencia cada vez mayor del mundo: "La novela moderna, de ninguna manera, pretende representar acontecimientos reales, ni tampoco como un Todo al mundo, tan impenetrable y a veces incomprensible a partir de ese momento. Ahora crea "segundos mundos" en los cuales afloran la variedad de intenciones y perspectivas actuales". ${ }^{77}$ Alejándose de la mímesis, "la realidad ficticia de la novela no es una ficción de la realidad sino "la ficción de la realidad de las realidades'. Ésta representa condiciones que en modo normal no pueden ser observadas en el mundo, a saber, condiciones bajo las que algo parece ser realista. Para que una novela sea realista, es preciso que no puede ser real" ${ }^{78}$ Hoy sabemos que la realidad es construida y, por lo mismo, que hay diversas posibilidades de observarla, de lo cual resultan otras tantas "realidades". Como esta autora explica, "la disponibilidad de mundos ficticios" nos permite observar "desde fuera" el que suponemos como "mundo verdadero" y de ese modo pensarlo de otra forma, "confrontarlo con otras alternativas". ${ }^{79}$ En particular la novela ha venido familiarizándonos con la idea de que la ficción no es un engaño o una ilusión. "La fiction se transforma en un espejo en el cual la sociedad refleja su propia contingencia, la normalidad de un mundo indefinible y poco concreto" ${ }^{80} \mathrm{O}$, en otros términos, es realista, mostrando que la realidad real es en buena medida inaprehensible, alejándonos de un realismo ingenuo. "En un mundo

\footnotetext{
surge para el observador hasta que existe algo de la cual puede ser diferenciada”. (Con respecto a la duplicación de la realidad, cita a Niklas Luhmann, Die Religion der Gesellschaft, Fráncfort del Meno, Suhrkamp. 2000, p. 58 ss.)

${ }^{77}$ Esposito, Die Fiktion, op. cit., p. I7. Ella señala en nota al pie que "Sobre el concepto de los 'segundos mundos', véase Blumenberg 1964 [Wirklichkeitsbegriff und Möglichkeit Romans], p. 2 I, Jauß I983”.

${ }^{78}$ Idem.

${ }^{79}$ Ibidem, p. I 8.

${ }^{80} \mathrm{Idem}$.
} 
cada vez más incomprensible, la realidad de la ficción se basa precisamente en la transparencia del engaño". ${ }^{81}$

Me parece que este concepto de ficción se aproxima al segundo de White cuando afirma que: "La novela modernista no está sino fijada en LA RELACIÓN DEL PASADO-PRESENTE, SUS ANOMALÍAS, SUS PARADOJAS Y SUS ABSURDIDADES. Es tan sólo que la novela modernista está más preocupada por 'EL PASADO PRÁCTICO’ que por su domesticada ( $y$, en la medida en que ha sido narrativizada, 'ficcional') 'contraparte histórica". ${ }^{82}$ Ya que si bien aquí sigue refiriéndose a la historiografía en términos de su primera acepción, cuando describe la "novela modernista" lo hace desde la segunda, en forma similar a Esposito, quien en otro apartado señala que "la fiction, parece ser, se torna aceptable como construcción ficticia, cuando presenta un mundo que es tan plausible que podría ser verdad". ${ }^{83}$ Y justo es éste el del practical past, el nuestro, por más intransparente, paradójico y absurdo que sea.

Pero -insisto- la pregunta sería si la historiografía que pueda ocuparse de ese practical past para reestablecer su conexión con el presente y su papel de magistra no tendría que acudir por necesidad a este segundo tipo de ficción, ya que de lo contrario, ¿cómo seguir las recomendaciones que el propio White le hace para lograr un cambio paradigmático?

${ }^{81}$ Ibidem, p. I6. Por su parte, White asienta en la n. I 2 del capítulo I de The Practical Past: "Para un repaso tanto de la novela posmodernista en Occidente, y de las problemáticas teóricas suscitadas por el resurgimiento de la novela histórica como un género dominante, ver Amy Elias, Sublime Desire: History and Post- 1960 Fiction, Baltimore, The Johns Hopkins University Press, 2001. Algún tiempo atrás, Linda Hutcheon seńaló que la novela posmodernista se consagró a la producción de lo que ella llamaba la "metaficción historiográfica", que caracterizó como lo que mostraba que la 'ficción estaba históricamente condicionada y la historia estaba discursivamente estructurada' [A Poetics of Postmodernism: History, Theory, Fiction, New York, Routledge, I988, I20]." Hayden White, The Practical Past, op. cit., p. Io6.

${ }^{82}$ Ibidem, p. 92.

${ }^{83}$ Esposito, Die Fiktion, op. cit., p. I 3. 
7) Apropiándome de White como un homenaje póstumo:

LA HISTORIA MAGISTRA VITAE HOY, O BIEN, ¿QUÉ HA DE REALIZAR LA HISTORIOGRAFÍA PARA SEGUIR A LA NOVELA POSMODERNA Y PERMANECER SIENDO HISTORIA?

“El estatus "científico" de la historia estaba salvado, pero a costa de la degradación de la historia de su rol tradicional como magistra vitae, al de una empresa de segundo orden que recolecta hechos" ${ }^{84}$ Con esta afirmación White inicia el Epílogo de su libro, para después mostrar cómo "en el siglo xx, la Historia servía aún a las comunidades proveyéndoles una consideración genealógica de la formación de identidades grupales. Una historia de una nación o pueblo, un grupo o una institución, proporcionaba el equivalente de una definición extensional de sus sustancia o esencia". ${ }^{85}$ Pero a medida que avanzaba el xx, y no se diga el xxI, la historiografía ha sido pinzada cada vez más por factores contextuales, en particular a partir de la crisis del "Estado Nación", ${ }^{86}$ y la consecuente de las identidades patrias, por un lado, en tanto que la propia crítica de la historiografía, inmersa en la de la Modernidad, la tomó, por el otro. Ambas pusieron cada vez más en claro el alejamiento de su papel como maestra ejemplar, ya predicho por Koselleck, pero que, sin embargo, es aún una cuenta no saldada. Aquí es donde White nos ha aportado con su practical past una vía de reflexión aguda, y una posible respuesta a la pregunta con la que cerré mi trabajo original.

Por el lado de la historiografía, White parte de la detección de un doble movimiento -que él mismo califica de irónico-, ya que en la medida en que la "novela modernista" rechazaba los grand récits de la historiografía, se aproximaba al tipo de escritura de la historia propuesta por los "herederos" del estructuralismo de

${ }^{84}$ White, The Practical Past, op. cit., p. 97.

${ }^{85}$ Ibidem, pp. I 29-I 30.

${ }^{86} \mathrm{Cfr}$. Jürgen Habermas, Más allá del Estado nacional. 
Braudel. ${ }^{87}$ Por supuesto que se trata de este tipo de novela, en la cual -según la glosa de Barthes que él mismo hace- "los eventos eran indeterminados, los personajes resultaban indiscernibles y las tramas virtualmente no existían". ${ }^{88}$ Por su cuenta, en efecto la historiografía científica se ha ido cada vez más hacia lo estructural y menos hacia lo narrativo, o bien ello ha pasado a ser el ejemplo del caso. Los conceptos y constructos con los que opera se han vuelto a su vez más abstractos y complejos, y muchas veces sólo accesibles a los especialistas de los abstrusos problemas que hoy se investigan. Se trata de la "historia ciencia", a la cual -y aquí me separo de White- no le queda más que ceñirse de manera explícita al código verdadero-falso, o sea, al código binario propio del "sistema ciencia", ${ }^{89}$ y desde mi personal óptica, ocuparse de la historia del "sistema sociedad", en la línea de la discusión abierta con las ciencias sociales desde la época braudeliana. Pero, a la vez es el propio White quien me permite ver una vía alternativa para concebir una historia que recupere su perdida función de "maestra" y pueda incidir en el presente de las personas. ¿Cómo es posible ello?

En términos del libro aquí analizado, todo su trabajo se orienta a la crítica de esa historia ciencia en cuanto a su función en el mundo contemporáneo, y las lecciones que le ofrece "la novela posmodernista" para conseguir un nuevo tipo de historiografía. En los ejemplos antes citados vimos cómo la narrativa no puede verse ya como el camino para la representación del pasado frente a la inexistencia de la coherencia, de la causalidad lineal y, en consecuencia, la dificultad de otorgar sentido a lo acontecido. También dimos cuenta de cómo ya no existiría el "evento histórico" como tal, sino un complejo de huellas de muy diverso tipo que muestran incluso el ocultamiento y la latencia detrás de lo evidente,

${ }^{87}$ Hayden White, “Reflexiones acerca del 'género' en los discursos de la historia”, p. 107.

${ }^{88}$ Idem.

${ }^{89}$ Cfr. Niklas Luhmann, La ciencia de la sociedad. 
pero sobre todo no documentables en los términos de "verdad" que requiere la historiografía científica. Y por último, con todo ello queda en vilo "el sujeto" -el personaje-como supuesto actor y responsable de la acción, si bien la reconceptualización de la "ficción" permitiría suponer sus intenciones y traer sus latencias al presente, cuando la plausibilidad contextual permite llevar a cabo esta operación. El "anacronismo" y el "presente como historia”, cerrarían esta contribución actualizante hacia la escritura histórica desde esta novela posmoderna. Pero aquí es precisamente donde cabe preguntarnos si, al realizar la historia ciencia, estas transformaciones, como lo propone White, no dejan de ser tales, para convertirse en otro tipo de escritura, ya que, como él mismo asienta, "la novela posmodernista no disuelve tanto como trasciende la distinción entre historia y literatura, al articular, de un modo diferente al del pasado, el concepto de 'ficción". ${ }^{90} \mathrm{Me}$ parece que sólo faltaría un último paso para afirmar que ésta sería una nueva escritura histórica autónoma a plenitud, más que un nuevo paradigma de la historia ciencia. No sé si a Hayden White le hubiera parecido bien esta salida radical, pero hay que señalar que muchas de sus propuestas apuntan hacia allá. ${ }^{91}$ Queda en el

\footnotetext{
${ }^{90}$ White, "Reflexiones acerca del 'género'...”, op. cit., p. Io6.

91 "Limitando mis acotaciones ahora a mi propia área de interés y a la hipótesis de que hay más de un camino para 'decir la verdad acerca del pasado'. Quiero sugerir que tanto la novela histórica como la historia novelesca son dos instancias de discursos no declarativos, que su verdad puede consistir menos en lo que aseveran a modo de verdad factual enunciada que en lo que connotan en otros modos y voces identificados en el estudio de la gramática: es decir, los modos de interrogación, conación, o coacción, y subjunción y las voces de acción, pasión y trasunción. Así, POR EJEMPLO, TENDRÍA MENOS SENTIDO RESPONDER A UN POEMA O A UNA NOVELA O A UNA HISTORIA EJECUTADA A MODO DE UNA PREGUNTA O DE UN DESEO CON LA DUDA, '¿ES ESTO VERDADERO?' QUE CUANDO SE RESPONDE A UNA EJECUTADA A MODO DE MANDATO. LA RESPUESTA 'ADECUADA' A UN MANDATO PODRÍA SER, 'SÍ, SEÑOR' O 'No, SEÑOR', PERO NO ES POR FUERZA (EN CASO DE QUE UN MANDATO SEA ENUNCIADO FUERA DE UNA RELACIÓN MILITAR O DE UNA DE AMO-ESClAVO) INAPROPIADO RESPONDER, COMO EN EL CASO DE BARTLEBY the SCRIVENER de Melville, con el predicado subjuntivo 'Preferiría no”'. White, The Practical Past, op. cit.. p. 32.
} 
tintero cómo denominar este género de saber, pero tal vez la referencia al practical past pudiera ser su denominador, y así, ésta sería la "historia práctica", heredera de la "historia magistra vitae".

Sin embargo, permanecería aún el problema de cómo esta nueva versión de historia podría guiar la acción en un mundo intransparente, contingente y alejado de la guía moral que la religión o la filosofía de la historia proporcionaban en el pasado. $\mathrm{Y}$ es aquí donde el otro brazo de la pinza aparece, como bien lo muestra White, pues lo que denomina el "evento moderno", no es otro que la traumática y enajenante experiencia de una identidad fragmentada y sin sentido generada por la Modernidad, encriptada en nuestro practical past. El pasado "de personas particulares, grupos, instituciones y agencias -esto es, el pasado que la gente como individuos o miembros de grupos derivan para ayudarse a hacer valoraciones y tomar decisiones en la vida cotidiana ordinaria así como en situaciones extremas (tales como catástrofes, desastres, batallas, conflictos judiciales y de otros tipos en que la supervivencia está en entredicho)".$^{92}$ Éste es el referente de esta historia, el cual tendrá que situarse y reaccionar frente al argumental y coherente historical past, para desde ahí, y aun sabiendo que no hay nada sustantivo, poder suponer -desde la ficción del "como si"- que en efecto contiene una sustancia a partir de la que podemos construir una identidad propia y responder, desde una moral común a nuestro entorno grupal, a la pregunta por el "qué hacer" en nuestra vida diaria. En palabras de White:

Pero, habiendo dicho todo esto, todavía queda pendiente el problema de la identificación de la substancia del "pasado práctico". O permaneceríamos en un problema si hubiéramos retenido el espejismo de que todo debe tener una substancia dentro, o detrás, o por encima, a fin de conferirle esa cosidad sin la que se desvanecería en la nada. Pero ese desvanecerse en la nada es el

${ }^{92}$ Ibidem, p. xiii.

I 24 / Perla Chinchilla 
destino de todas las cosas cuya substancia es la materia. Entretanto, necesitamos el espejismo de la substancia -la noción de que las cosas sí tienen substancia en la medida en que somos capaces de conferírselas con esto y tratarlas como si la merecieran siempre y cuando acataran el reto de actuar, aunque fuera de vez en vez y sólo hasta cierto punto efectivamente, en lugar de someternos a la autoridad de aquellos que reclaman el derecho de decirnos quiénes somos, qué se supone que deberíamos hacer y a qué deberíamos aspirar para ser. ${ }^{93}$

A esta "historia práctica" le tocaría sustraer al presente de la pura "pastología" a la que White hace referencia, logrando explicitar las estructuras que historiza la historiografía científica -la historia del "sistema sociedad" - como condiciones de posibilidad que dan cuenta de lo "latente", y por tanto no perceptible a primera vista para las personas de carne y hueso, y con ello ayudarlas a que decidan por su cuenta "qué hacer". Me parece que por aquí podría vislumbrarse una salida al actual "limbo" historiográfico que White detecta -entre lo científico y lo práctico-, y así conseguir una propuesta para desarrollar una nueva Historia Magistra. Termino con la misma cita de Hilary Putnam con la que cerré mi viejo texto, y con la cual me parece que Hayden White estaría de acuerdo:

Reconocer que un ser humano leal es mejor que un ser humano desleal, que una persona capaz de philia es mejor que una persona incapaz de philia, que una persona capaz de sentido de la comunidad o de ciudadanía en una polis, es mejor que una persona incapaz de sentido de la comunidad o de ciudadanía en una polis, etc., no es decir que cualquiera de estos valores o cualesquiera de estas imágenes morales, que pueden subyacer a estos

\footnotetext{
${ }^{93}$ Ibidem, p. I03. Cfr. Niklas Luhmann, La religión de la sociedad. 94 “[E]n lo que llamaría 'pastología': estudios de memoria, historiografía oral, literatura testimonial, narratología, estudios de la consciencia, teoría de especies, posthumanismo, estudios subalternos, y afines". Ibidem, p. 99.
} 
valores y organizarlos, sea última, en el sentido de ser exclusiva o exhaustivamente correcta. Nuestras imágenes morales están en un proceso de desarrollo y reforma. Pero esto quiere decir que en cada nivel de este desarrollo y reforma habrá lugares, muchos lugares, en los cuales tengamos que decir: "Aquí es donde mi pala se dobla”. ${ }^{95}$ 娄

\section{Bibliografía}

Castro Orellana, Rodrigo. "Michel de Certeau: historia y ficción", Ingenium. Revista de Historia del Pensamiento Moderno, núm. 4, dedicado a Metodología, julio-diciembre 2010, pp. I07-I24.

Chinchilla Pawling, Perla. “¿Aprender de la historia o aprender historia?”, Historia y Grafía, núm. I 5, 2000, pp. I I9-1 50.

DeLillo, Don. Submundo, Barcelona, Circe, 2000.

Esposito, Elena. Die Fiktion der wahrscheinlichen Realität, Suhrkamp, Fráncfort del Meno, 20I4 (2007).

"Francois Hartog: el nacimiento del discurso histórico occidental" (entrevista de Alfonso Mendiola), Historia y Grafía, núm I I, I998, pp. I 53-I70.

Habermas, Jürgen. Más allá del Estado nacional, Madrid, Trotta, I995.

Koselleck, Reinhart. Futuro pasado: para una semántica de los tiempos modernos, Barcelona, Paidós, I 993.

Luhmann, Niklas. El arte de la sociedad, México, Herder/Universidad Iberoamericana, 2005 (1995).

- La ciencia de la sociedad, tr. de Silvia Pappe, Brunhilde Erker y Luis Felipe Segura, México, Anthropos/Universidad Iberoamericana/ ITESO, 1996.

- La religión de la sociedad, Madrid, Trotta, 2007.

Mailer, Norman. Los desnudos y los muertos, tr. Patricio Canto, Barcelona, Anagrama, 2018.

Putnam, Hilary. Las mil caras del realismo, Barcelona, Paidós, 1994.

Pynchon, Thomas. V., Barcelona, Tusquets, 2016.

Tozzi, Verónica. "Hayden White y el pluralismo conversacional", en Verónica Tozzi y Julio Bentivoglio (comps.), Hayden White: cuarenta años de

${ }^{95}$ Hilary Putnam, Las mil caras del realismo, pp. 46-47 y I 60. 
"Metahistory". Del "pasado histórico" al "pasado práctico", Buenos Aires, Prometeo, 2016, pp. 2II-224.

White, Hayden. "Reflexiones acerca del 'género' en los discursos de la historia”, Historia y Grafía (expediente "Géneros históricos"), núm. 32, 2009, pp. 9I-I07.

_. "The Modernist Event", en Figural Realism: Studies in the Mimesis Event, Baltimore, The Johns Hopkins University Press, I999, pp. 66-86.

. "The Practical Past", en Historein, vol. ıо, 20 го, pp. го-г9.

. The Practical Past, Illinois, Northwestern University Press, 2014. 